\title{
Penerapan Enterprise Architecture Pada Penerimaan Mahasiswa Baru Menggunakan TOGAF Di Universitas X Palembang
}

\author{
Lathifah $^{* 1}$, Suaidah $^{2}$ \\ Jurusan Informatika, Universitas Teknokra Indonesia \\ Jl. Z.A Pagar Alam No.9-11, Labuhan Ratu, Kec.Kedaton, \\ Kota Bandar Lampung - Indonesia 35132. Telp/fax (0721) 702022 \\ e-mail: ${ }^{* 1}$ Lathifah@teknokrat.ac.id, ${ }^{2}$ Suaidah@teknokrat.ac.id
}

\begin{abstract}
Abstrak
Enterprise architecture sangat diperlukan oleh semua organisasi salah satunya yaitu universitas, universitas memiliki banyak sektor bisnis didalamnya salah satunya yaitu pada sistem penerimaan mahasiswa baru. Sistem penerimaan mahasiswa baru yang dimiliki oleh universitas X Palembang memiliki beberapa kendala dalam mengelolanya. Apakah dengan diterapkannya proses enterprise architecture proses bisnis yang ada bisa terintegrasi dengan baik? Metodologi penilaian penerapan tersebut menggunakan TOGAF yang mengacu pada proses architecture business, architecture data, architecture application, dan architecture technology. Hasil penerapan yang didapat dari nilai tersebut yaitu memiliki nilai rata-rata 2,23\% dengan kata lain penerapan enterprise architecture pada Universitas X Palembang telah digunakan dengan baik pada sistem penerimaan mahasiswa baru sehingga dapat berjalan dan terintegrasi menjadi satu, serta bisa dijadikan referensi dalam menerapkan enterprise architecture berikutnya pada sistem-sistem yang lain di universitas $x$. Adapun masalah yang muncul yaitu data pada penerimaan mahasiswa baru belum dikelola dengan baik dokumentasinya, sehingga Universitas X Palembang mengalami kesulitan dalam mengelolanya.
\end{abstract}

Kata kunci: Enterprise Architecture, Penerapan, PMB, TOGAF, Universitas.

\begin{abstract}
Company architecture is needed by all organizations, one of which is the university, the university has many business sectors in it, one of which is the new student admission system. The new student admission system owned by $X$ Palembang university has several things in managing it. Can the implementation of company process architecture make existing business processes be properly integrated? The application methodology uses TOGAF which refers to business architecture processes, architectural data, architectural applications, and architectural technology. The application results obtained from this value, which has an average value of $2.23 \%$ in other words the application of corporate architecture at X Palembang University has been used well in the new student admission system so that it can run and be integrated into one, and can be used as a reference in application. the next enterprise architecture on other systems at the university $\mathrm{x}$. As for the problems that arise, the data on the admission of new students has not been properly managed, so the documentation is so that the X Palembang University has difficulty managing it.
\end{abstract}

Keywords: Enterprise Architecture, Implementation, PMB, TOGAF, University. 


\section{PENDAHULUAN}

Perkembangan teknologi pada saat ini sangat menjadi prioritas di dunia pendidikan, Universitas x Palembang memandang penting perubahan tersebut dikarenakan untuk memenuhi kebutuhan proses bisnis yang terintegrasi dengan baik maka memudahkan semua kinerja dengan sistematis. Cakupan penelitian ini di bagian PMB (Penerimaan Mahasiswa Baru) yaitu membahas proses penerimaan mahasiswa baru, pendaftaran mahasiswa, sampai pengarsipan data-data yang ada dibidang akademik serta memudahkan mahasiswa ataupun calon mahasiswa dalam mengakses Universitas X. Dalam mengelola bagian PMB (Penerimaan Masiswa Baru) terdapat duplikat data, aplikasi error, dan jaringan yang lemah, sehingga sering mengalami kegagalan. Supaya tidak terjadi permasalahan tersebut Universitas X Palembang membutuhkan unit bisnis data, aplikasi, jaringan terintegrasi satu sama lain. Cara untuk mengintegrasikannya yaitu dibutuhkan enterprise architecture yang telah digunakan untuk dijadikan acuan serta TOGAF dipakai untuk menentukan proses bisnis, data, aplikasi, dan teknologi yang digunakan agar selaras dengan sistem penerimaan mahasiswa baru.

Enterprise merupakan sekumpulan organisasi yang memiliki beberapa tujuan atau prinsip umum dan atau suatu garisan dasar [1]. Enterprise architecture adalah sebuah pendekatan logis, komprehensif, dan holistik untuk merancang dan mengimplementasikan sistem dan komponen sistem secara bersamaan yang meliputi suatu infrastruktur manajemen informasi teknologi [2]. Perguruan tinggi sangat membutuhkan TI untuk menyelaraskan tujuan awal (visi) dalam menjalankan proses bisnis yang ada, dengan adanya keselarasan tersebut maka akan mempermudah semua kinerja secara sistematis sesuai dengan proses bisnis. Semua proses bisnis harus terintegrasi dengan baik yang meliputi kebutuhan secara menyeluruh mulai dari organisasi, arsitektur data yang digunakan, arsitektur aplikasi yang dibangun, serta arsitektur teknologi yang digunakan jika terjadi integrasi yang tidak baik maka dapat menyebabkan kegagalan pada proses secara keseluruhan [3].

TOGAF merupakan rancangan model architecture yang sesuai dengan visi dan misi Universitas x serta dapat diterapkan pada Universitas lain yang mempunyai kesamaan dalam proses bisnis [4]. Dalam pengembangan TOGAF meliputi empat jenis terkait architecture yang umum diterima sebagai himpunan bagian dari enterprise architecture yaitu architecture business, architecture application, architecture data, dan architecture technology [5]. Ada 4 proses AE yang akan digunakan adalah proses bisnis, data, aplikasi, dan teknologi bisa dilihat pada gambar 1.

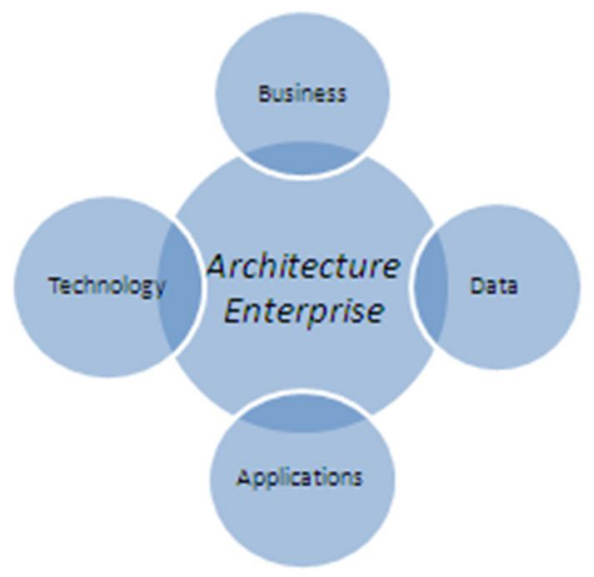

Gambar 1. Proses Enterprise Architecture 
Aspek enterprise architecture pada sistem penerimaan mahasiswa baru menarik diteliti karena sistem pada Universitas X Palembang sulit untuk terintegrasi satu sama lain [6]. Oleh sebab itu penerapan enterprise architecture pada universitas $\mathrm{x}$ belum digunakan secara optimal sesuai dengan kebutuhan. Penelitian akan membahas bagaimana universitas x menganggap begitu penting enterprise architecture dalam sistem penerimaan mahasiswa baru. Tujuan dilakukan penelitian ini untuk mendapat gambaran penerapan enterprise architecture pada univeritas serta menambah pengetahuan tentang penerapan enterprise architecture.

\section{LANDASAN TEORI}

Perguruan tinggi mempunyai beberapa unit bisnis yaitu bagian kepegawaan, akademik, keuangan, penerimaan mahasiswa baru, sistem informasi dan teknologi. Unit bisnis tersebut harus saling terintegrasi satu sama lain agar memudahkan kinerja unit bisnis terpusat menjadi satu, adapun manfaat potret enterprise architecture pada perguruan tinggi yaitu untuk dijadikan pedoman serta acuan sebuah model yang bisa digunakan dalam jangka waktu yang panjang [7]. Perguruan tinggi pada umunya memiliki beberapa unit bisnis seperti: bagian umum, keuangan, kepegawaian, perencanaan dan sistem informasi, penerbitan dan publikasi, serta kegiatan utama penerimaan mahasiswa, operasional akademik dan wisuda. Masing-masing unit bisnis memiliki domain sistem yang dikembangkan sendiri, sehingga sering terjadi bentrok dalam pengalokasian sumber daya, data yang digunakan tidak konsisten karena tidak diolah secara real time, pengelolaan domain sistem berorientasikan pada data, bukan berorientasi pengguna [8].

Peneliti N Anissa et al (2019) [9] membangun sebuah aplikasi yang guna mempermudah sistem penilaian kinerja para pegawai negeri sipil untuk memberikan pelayanan publik kepada para masyarakat, aplikasi yang dibuat menggunakan teknologi dari konsep Smart City sebagai solusi untuk menangani permasalahan saat ini. Metode penilaian menggunakan TOGAF yang mengacu pada pedoman atau metode baku enterprise architecture, dengan adanya pedoman mempermudah peneliti dalam membuat aplikasi sistem penilaian kinerja pegawai negeri sipil. Enterprise architecture didalamnya menyelaraskan hubungsn strategi dengan proses bisnis yang dapat digunakan jangka panjang, serta mendukungnya peningkatan kualitas demi tercapainya tujuan strategis akademik umumnya pada Perguruan Tinggi [10].

Menurut Sardi \& Surendro [11] dalam penelitiannya menyebutkan bahwa dalam pelaksanaannya, proses merger memiliki banyak tantangan pada tahap integrasi pascamerger, suatu proses integrasi yang bermasalah dapat memicu perubahan yang luar biasa serta berakibat fatal yaitu gagal. Untuk menanggulangi masalah yang akan muncul pada tahap integrasi yaitu dibuatnya perancangan arsitektur enterprise yang baik agar terjadi keselarasan antara teknologi informasi dan kebutuhan bisnis pada perguruan tinggi tersebut. Kemampuan dan sumber daya dalam deskripsi enterprise architecture. fokus secara khusus pada sumber daya, kapabilitas dan kompetensi konsep yang Unified Foundational Ontologi (UFO). Dalam kasus dunia nyata dimodelkan dengan metamodel diusulkan untuk mengatasi masalah diidentifikasi, dengan demikian meningkatkan kejelasan semantik dan untuk menunjukan penerapan konstruksi hubungan dalam pengaturan architecture enterprise. [12].

Penggunaan Framework TOGAF juga diterapkan untuk pemodelan Sistem Informasi Akademik pada institusi XYZ.. Dalam menunjang kegiatan organisasi untuk fungsional akademik digunakanlah Sistem Informasi Akademik (SIAKAD). Sistem informasi harus dirancang dengan baik sesuai dengan perencanaan sistem agar tidak terjadi kegagalan dan masalah dalam sistem yang disebabkan tidak adanya perencanaan sistem yang jelas, dan teknologi informasi yang dapat mendukung jalannya sistem informasi tersebut. Untuk menciptakan keselarasan strategi bisnis dan teknologi informasi organisasi dirancang sebuah enterprise architecture. TOGAF ADM digunakan sebagai framework. TOGAF ADM yang 
berfungsi untuk mendefinisikan arsitektur baseline, menentukan model bisnis dan merancang arsitektur target yang menghasilkan sebuah blueprint arsitektur sebagai dasar pembangunan dan pengembangan sistem informasi akademik (SIAKAD) di institut XYZ [14]. Pemanfaatan $e$ academic pada politeknik harapan bersama saat ini terjadi tumpang tindih, agar tidak terjadi hal tersebut maka diterapkan enterprise arsitecture guna membuat, merancang, mengelola sistem yang berjalan saat ini. Framework TOGAF digunakan untuk menghasilkan blue print pada sistem yang dimana proses bisnis saling terintegrasi, serta mempercepat pendistribusian atau penyebaran informasi sehingga lebih efektif dan efesien [15].

Penerapan enterprise architecture menurut Adi [13] setiap organisasi harus memiliki visi, misi, dan strategi bisnis keperubahan yang lebih efektif dalam mengembangkan sistem informasi yang terintegrasi. Supaya bisa menyusun perencanaan sistem informasi yang tepat serta dapat menghasilkan sebuah enterprise architecture dalam bentuk blue print diperlukan kerangka kerja menggunakan TOGAF. Hasil dari dokumentasi tersebut bisa dijadikan acuan atau dapat dikembangkan kembali sesuai dengan kebutuhan.

\section{METODE PENELITIAN}

Tahapan ini akan menjelaskan apa saja yang dilakukan penulis dari awal hingga akhir. Agar lebih gampang memahaminya bisa dilihat pada Gambar 2 Diagram Alur Penelitian.

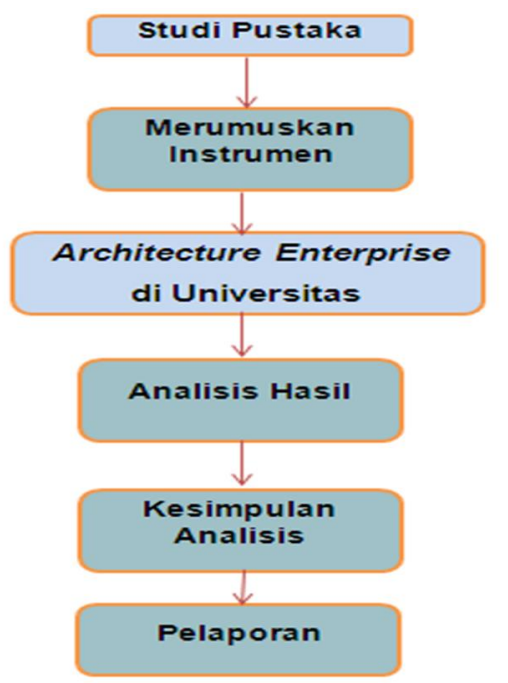

Gambar 2. Diagram Alur Penelitian

1. Studi Pustaka

Tahap Awal melakukan studi pustaka, dibutuhkan untuk membandingkan serta mengetahui penelitian sebelumnya yang berkaitan dengan enterprise architecture, proses bisnis, infrastruktur, dan TOGAF.

2. Merumuskan instrumen

Peneliti melakukan wawancara dengan pihak universitas $\mathrm{X}$ untuk mengetahui data yang terkait dalam proses bisnis, data, aplikasi, dan teknologi. Setelah melakukan pengumpulan data dan observasi maka penulis menemukan titik terang terkait data dan informasi pada universitas X Palembang. Maka penulis merumuskan pertanyaan, untuk mengetahui penerapan enterprise architecture yang telah digunakan pada Universitas X Palembang. 


\section{Enterprise architecture}

Pada proses ini peneliti melakukan survey ke Universitas X Palembang melihat secara langsung enterprise architecture yang telah digunakan. Adapun 4 bagian proses yang meliputi architecture business, architecture data, architecture applications, dan architecture technology. Data yang sudah didapat dikelompokan lalu langsung divalidasi, hasil perhitungan menggunakan proses statistik.

4. Analisis Hasil

Hasil analisis menggunakan data kuantitatif yang telah terkumpul dari hasil validasi. Hasil perhitungan menggunakan skala rentang 1 sampai 3 , dari skala itu kita bisa mengetahui bahwa enterprise architecture sudah berjalan dengan baik atau masih perlu ditingkatkan dalam menjalankan proses bisnisnya serta infrastruktur sudah ada saat ini mendukung jalanya proses bisnis.

5. Kesimpulan Hasil

Menjelaskan kesesuaian hasil perhitungan dengan proses bisnis yang diterapkan pada universitas $x$ Palembang.

6. Pelaporan, dan Publikasi

Peneliti melaporkan hasil kepada pihak Universitas X Palembang serta mempublikasikan penulisan dalam bentuk jurnal.

\section{HASIL DAN PEMBAHASAN}

Fokus penelitian ini yaitu pada manfaat menerapkan enterprise architecture di Universitas X Palembang pada sistem penerimaan mahasiswa baru, serta membuat question untuk mengetahui seberapa besar peran enterprise architecture dalam integrasi proses bisnis. Hasil dari manfaat tersebut berupa besarnya skala. Pertanyaan yang dibuat didapat dari beberapa literature riview dan dokumen universitas $\mathrm{X}$ Palembang, lalu dijadikan referensi dalam mengelompokan proses enterprise architecture. Pada TOGAF terdapat proses enterprise architecture yaitu architecture business, architecture data, architecture application, dan architecture technology. Ada 15 (lima belas) question yang telah dibuat bisa dilihat pada Tabel 1.

Tabel 1. Pengelompokan Question pada Proses TOGAF

\begin{tabular}{|c|c|c|}
\hline No. & Proses Enterprise Architecture & Question \\
\hline Q1 & Architecture Business & $\begin{array}{l}\text { Proses bisnis yang berjalan sudah selaras } \\
\text { dengan IT. }\end{array}$ \\
\hline Q2 & Architecture Business & $\begin{array}{l}\text { Proses bisnis yang dimiliki Universitas X } \\
\text { sudah berjalan dengan efektif ketika } \\
\text { Enterprise architecture diterapkan. }\end{array}$ \\
\hline Q3 & Architecture Business & $\begin{array}{l}\text { Proses bisnis mampu mengelola data pada } \\
\text { setiap fungsi bisnis. }\end{array}$ \\
\hline Q4 & Architecture Data & $\begin{array}{l}\text { Format data yang digunakan sudah } \\
\text { terstruktur }\end{array}$ \\
\hline Q5 & Architecture Data & Duplikat data tidak ada. \\
\hline Q6 & Architecture Data & Keamanan data terjaga dengan baik. \\
\hline Q7 & Architecture Data & $\begin{array}{l}\text { Data hak akses telah sesuai dengan hak } \\
\text { akses. }\end{array}$ \\
\hline
\end{tabular}




\begin{tabular}{|c|l|l|}
\hline Q8 & Architecture Data & $\begin{array}{l}\text { Data terintegrasi dan terpusat menjadi } \\
\text { satu. }\end{array}$ \\
\hline $\mathbf{Q 9}$ & Architecture Application & Redudansi dalam aplikasi. \\
\hline $\mathbf{Q 1 0}$ & Architecture Application & $\begin{array}{l}\text { Integrasi dengan aplikasi lain berjalan } \\
\text { kondusif. }\end{array}$ \\
\hline $\mathbf{Q 1 1}$ & Architecture Application & Aplikasi mudah digunakan (user friendly) \\
\hline $\mathbf{Q 1 2}$ & Architecture Technology & $\begin{array}{l}\text { Enterprise architecture pada penerimaan } \\
\text { mahasiswa baru dilakukan secara terpusat. }\end{array}$ \\
\hline $\mathbf{Q 1 3}$ & Architecture Technology & $\begin{array}{l}\text { Sistem penerimaan mahasiswa baru telah } \\
\text { terdokumentasi dengan baik. }\end{array}$ \\
\hline $\mathbf{Q 1 4}$ & Architecture Technology & $\begin{array}{l}\text { Maintenance sistem telah dilakukan } \\
\text { penjadwalan. }\end{array}$ \\
\hline $\mathbf{Q 1 5}$ & Architecture Technology & $\begin{array}{l}\text { Teknologi Infomasi pada universitas X } \\
\text { mendukung jalannya sistem penerimaan } \\
\text { mahasiswa baru? }\end{array}$ \\
\hline
\end{tabular}

Nilai bobot yang digunakan dalam penerapan enterprise architecture pada Universitas $\mathrm{X}$ Palembang yaitu bobot 1 sampai 3 yang artinya ada kata cukup, baik, dan sangat baik. Berikut skor nilai yang digunakan pada penerapan enterprise architecture pada Universitas X Palembang terdapat pada Tabel 2.

Tabel 2. Skor Nilai

\begin{tabular}{|c|c|}
\hline Nilai Bobot & Keterangan \\
\hline 3 & Sangat Baik \\
\hline 2 & Baik \\
\hline 1 & Cukup \\
\hline
\end{tabular}

Berikut ini adalah hasil pengujian penerapan enterprise architecture pada Universitas $\mathrm{X}$ Palembang dengan menggunakan TOGAF pada Tabel 3. 
Tabel 3. Pengujian Penerapan Enterprise Architecture

\begin{tabular}{|c|c|c|c|c|}
\hline PERTANYAAN & Business & Data & Application & Tecnolog: \\
\hline Q1 & 2 & 2 & 2 & 2 \\
\hline Q2 & 2 & 3 & 2 & 3 \\
\hline Q3 & 3 & 2 & 2 & 2 \\
\hline Q4 & 2 & 3 & 2 & 2 \\
\hline Q5 & 2 & 3 & 2 & 2 \\
\hline Q6 & 2 & 3 & 2 & 2 \\
\hline Q7 & 2 & 3 & 3 & 2 \\
\hline Q8 & 2 & 3 & 3 & 2 \\
\hline Q9 & 2 & 3 & 3 & 2 \\
\hline Q10 & 2 & 2 & 3 & 2 \\
\hline Q11 & 2 & 2 & 2 & 2 \\
\hline Q12 & 2 & 2 & 2 & 3 \\
\hline Q13 & 2 & 2 & 2 & 2 \\
\hline Q14 & 2 & 2 & 3 & 2 \\
\hline Q15 & 3 & 2 & 2 & 2 \\
\hline TOTAL & 29 & 39 & 35 & 32 \\
\hline$\%$ compliance & $1,9 \%$ & $2,6 \%$ & $2.3 \%$ & $2,1 \%$ \\
\hline
\end{tabular}

Hasil perhitungan dari tabel 3 diatas dapat disimpulkan bahwa penerapan enterprise architecture pada Universitas X Palembang sudah hampir sangat baik digunakan terlihat pada architecture data $2,6 \%$ yang hampir mendekati skala 3, sedangkan architecture application $2,3 \%$ dan architecture technology $2,1 \%$ sudah baik menggunakannya berada diskala 2, pada architecture business $1,9 \%$ menandakan bahwa proses bisnis yang berjalan cukup terintegrasi. Hasil perhitungan nilai terbesar terdapat pada architecture data 2,6\%. Kurva Hasil bisa dilihat pada gambar 3.

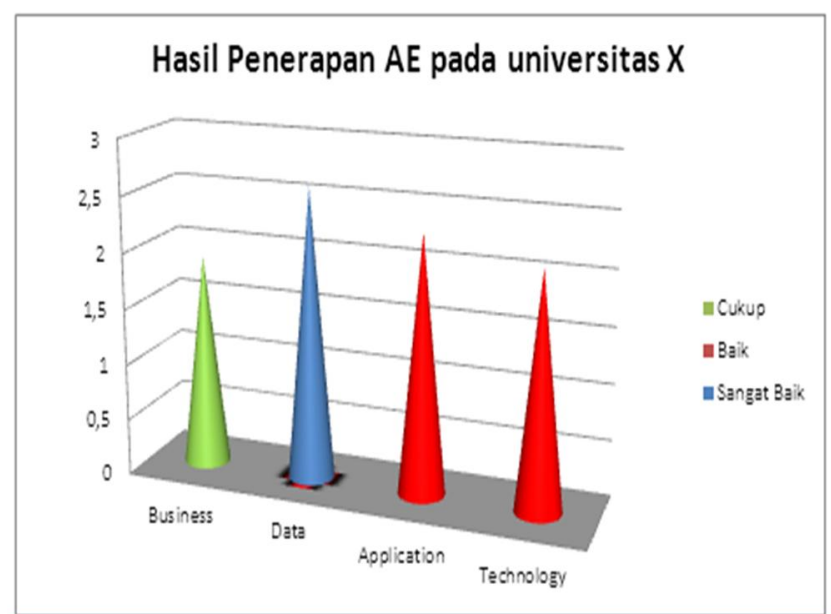

Gambar 3. Hasil Penerrapan Enterprise Architecture pada Universitas X Palembang

Hasil penerapan enterprise architecture pada Universitas X Palembang dengan skala nilai sangat baik, dan cukup bisa gunakan dengan baik. Dilihat pada Gambar 3 bahwa rata-rata dari hasil penerapan enterprise architecture yaitu $2,23 \%$ yang artinya penerapan enterprise architecture berada pada skala 2 (dua) dengan keterangan baik secara keseluruhan proses. 


\section{KESIMPULAN}

Penerapan enterprise architecture pada Universitas X Palembang sangat bermanfaat dalam menjalankan proses bisnisnya pada penerimaan mahasiswa baru. Beberapa literature riview dijadikan acuan dalam membuat 15 (lima belas) pertanyaan, TOGAF digunakan sebagai pedoman mengukuran penerapan enterprise architecture pada Universitas X Palembang yang meliputi architecture business, architecture data, architecture application, dan architecture technology. Hasil dari pertanyaan diberi nilai, nilai yang didapat diolah secara statistik dan dijadikan patokan nilai dalam penerapan enterprise architecture pada Universitas X Palembang. Rentang nilai yang didapat yaitu berada pada skala 2 (Baik) dalam penerapan enterprise architecture pada Universitas X Palembang. Kesimpulan yang dapat ditarik adalah penerapan enterprise architecture pada Universitas X Palembang telah digunakan dengan baik pada sistem penerimaan mahasiswa baru dapat berjalan dan terintegrasi menjadi satu, serta bisa dijadikan referensi dalam menerapkan enterprise architecture berikutnya pada sistem-sistem yang lain di universitas x. Adapun masalah yang muncul yaitu data pada penerimaan mahasiswa baru belum dikelola dengan baik dokumentasinya, sehingga Universitas X Palembang mengalami kesulitan dalam mengelolanya

\section{SARAN}

Penelitian ini terdapat beberapa hal yang bisa dikembangkan untuk penelitian selanjutnya yaitu mengukur manajemen resiko dalam rencana implementasi TOGAF. Rencana implementasi tak lain merupakan suatu rencana proyek berskala besar untuk mengimplementasikan cetak biru yang telah dihasilkan. Untuk itu, perlu dimasukkan unsur untuk meminimalkan risiko-risiko yang mungkin terjadi demi keberhasilan implementasi.

\section{UCAPAN TERIMA KASIH}

Penulis mengucapkan terima kasih kepada Kementrian Riset dan Teknologi / Badan Riset dan Inovasi Nasional (BRIN) yang memberikan dana hibah, LPPM telah banyak membantu penulis dari awal sampai akhir, dan terimakasih kepada Universitas Teknokrat Indonesia Lampung sudah membuka pintu selebar-lebarnya bagi para dosen untuk berkarya.

\section{DAFTAR PUSTAKA}

[1] M. Lankhorst, 2009, "Enterprise Architecture at Work.," Berlin: Springer.

[2] Y. Parizeau, 2002, "Enterprise Architecture for Complex Government and the Challenge of Government On-line in Canada," Dalhoussie University.

[3] P. Srivastava, 1986, "Shifting Cultivation: Problem and Alternatives," Bangkok, FAO, p. In: Field Document 10.

[4] R. e. a. Setiawan, 2015, "Perancangan Enterprise Architecture.," Journal Teknologi Technoscientia, p. Volume 5 (2).

Suaidah, et., al [Penerapan Enterprise Architecture pada Penerimaan Mahasiswa Baru Menggunakan TOGAF di Universitas X Palembang] 
[5] A. e. a. Josey, 2011, "TOGAF Version 9.1 A Pocket Guide," Van Haren Publishing 1(December).

[6] R. Setiawan, 2015, "Perancangan Arsitektur Enterprise untuk Perguruan Tinggi Swasta Menggunakan TOGAF ADM," Jurnal Algoritma, pp. Volume 12, No.1, ISSN: 23027339.

[7] T. d. h. Lathifah, 2017, "Potret Enterpirse Architectur Perguruan Tinggi di Indonesia," Teknologi Technosscientia, Volume 10, No.1, ISSN: 1979:8415.

[8] A. P. Utomo, 2014, "Pemodelan Arsitektur Enterprise Sistem Informasi Akademik pada Perguruan Tinggi Menggunakan Enterprise Architecture Planning," Jurnal SIMETRIS, pp. volume 5. No.1, ISSN:2252-4983.

[9] L. e. a. Nur Anissa, 2019, "Analisis dan Perancangan Enterprise Architecture Menggunakan TOGAF ADM pada Fungsi Pemerintahan Dalam Sistem Manajemen Penilaian Performa Berbasis Smart City., " eProceeding of Engineering, p. Volume 6(2): 772.

[10] R. Rismiyati, 2016, "Analisis Penerapan Arsitektur Enterprise Pada Bagian Akademik Perguruan Tinggi (Studi kasus STMIK Bumigora Mataram)," Indonesian Journal on Networking and Security, pp. Volume 5 No.2, ISSN:2354-6654.

[11] K. S. Suhendro, 2016, "Rekomendasi Perancangan Arsitektur Enterprise Pascamerge," Studi Kasus Universitas Telkom. Ind Journal on Computing, pp. Vol.1, issue.1, pp.61-76.

[12] C. L. B. e. a. Azevedo, 2015, "Modeling Resources and Capabilities in Enterprise Architecture: A Well-Founded Ontology-Based Proposal for ArchiMate.," Information Systems, p. 235-62.

[13] R. Adi P Sumpena dan Roestam, 2020, "Penerapan TOGAF ADM untuk Perencanaan Enterprise Architecture Sistem Informasi pada UPT BKN Jambi," Jurnal Manajemen Sistem Informasi, pp. Volume 5, No.1, ISSN:2528-0082.

[14] R. Manolita, 2016, "Perancangan Business Architucture Untuk Fungsi Akademik pada Institut XYZ Menggunakan Framework Togaf Adm Studi Kasus Sistem Informasi Akademik (Siakad)," Jurnal Rekayasa Sistem dan Industri, pp. Volume 3, No.1, p.33-39, ISSN:2579-9142.

[15] S. G. Wiro, 2017, "Pemanfaatan Model Enterprise Architecture pada E-Academic Politeknik Harapan Bersama," CESS: Journal of Computer Engineering System and Sclence., pp. Volume 2, No.2, ISSN:2502-7131. 